\title{
Multimedia Internet-Based Platform Project for Saudi Students' English Language Learning
}

\author{
Basim H. Alahmadi \\ Madinah College of Technology, Madinah, KSA \\ Email: bassiem@yahoo.com
}

Received 22 February 2015; accepted 11 March 2015; published 13 March 2015

Copyright (C) 2015 by author and Scientific Research Publishing Inc.

This work is licensed under the Creative Commons Attribution International License (CC BY). http://creativecommons.org/licenses/by/4.0/

c) (i) Open Access

\begin{abstract}
This paper sets out to shed light on the hierarchical stages of producing technology-enhanced learning software designed to promote English language learning of Saudi students at Madinah College of Technology, Saudi Arabia. The aim of the software was to meet the learners' language needs, which defined the learning objective. The paper highlights how suitable language learning theories were implemented by coordinating the interface design theories and principles underpinning the production process. Toward the end of the paper, an evaluation of the strengths and weaknesses of the software is investigated. Finally, the prospects of the software's future work are presented.
\end{abstract}

Keywords

Technology-Enhanced Educational Material, Design Theories, User-Interface

\section{Defining the Aim of This Project: Objectives and Learners' Needs}

It is axiomatic that designing and producing any technology-enhanced learning material are a complicated process of two parts: theoretical and technical. By the theoretical part, we mean the design process, e.g., planning and making the blueprints, whereas the technical part means the actual construction, e.g., programming. These two parts must be dealt with equally according to the existing academic background. The theoretical part always dominates the technical part, because the latter is defined by the earlier.

The aim of this software originated from the absence of interaction in Saudi English classrooms, a major deficiency in Saudi English as a foreign language EFL class [1]. Therefore, this project was initiated exclusively to act as a catalyst to fill this gap. The author created a software called "Support Your Football Team!”. As the 
name indicates, the program entices students to practice their language while discussing one of their biggest personal interests, football. Thus, four international football teams were selected according to their high percentage of supporters among Saudi students. Regrettably, the selection of those teams relied on the author's 15-year teaching experience in Saudi EFL classrooms, and not on methodological results. The four teams were: F. C. Barcelona (Spain), Manchester (UK), AC Milan (Italy), and Ajax (Holland). They were from different countries so as to foster more interaction and enthusiasm between the learners.

Next, we need to describe the learning objectives of this software. As discussed above, the football factor was incorporated to augment the students' interaction. This interaction was attained after successfully receiving comprehensible input and producing conceivable output. Accordingly, the object of constructing this software was to produce interaction through comprehensible input and conceivable output among the interlocutors, i.e., the students.

The aims and objectives were built on the learners' needs. Learners' needs can be measured by conducting a Needs Analysis (NA). NA is a relatively new concept to language teaching. Yet, NA has long been conducted unconsciously by teachers and other stakeholders (a group of people who have the right to have input into the curriculum process) at schools to assess their learners' "language competence". Reference [2] defined NA as "techniques and procedures for obtaining information from and about learners to be used in curriculum development”.

Many researchers believe that learners' needs are crucial to the design of technology-enhanced educational materials [1] [3] [4]. Reference [5] made "identifying learners' needs" the first step of their seven-step model for the production of educational materials. As for interactive multimedia production, reference [6] proposed that there are two approaches: a technology-driven approach and a learner-based approach. He (ibid) posited that designers need to concentrate on learner-based models rather than relying solely on technology-driven models that are created only for aesthetic purposes.

Given this swift outline of the significance of learners' needs in educational software, let us now shed light on Saudi students' needs. The author used Jolly and Bolitho's seven-step model and began the first step (identifying learners' needs) by identifying the targeted learners' needs. These needs were spelled out by [7] as follows:

1) Poor linguistic competence.

2) Negative attitudes toward Language 2 L2.

3) Shyness and inhibition.

4) English is not supported outside the classroom.

This software was designed to address these deficiencies. The first weakness could be improved by increasing the students' language output. The second pitfall was hoped to be addressed by using the students' enthusiasm for their teams as a vehicle to learn language. The third seemed to be avoided by introducing the chat facility, where anonymity was maintained with avatars and aliases. The fourth problem was handled by the technology's mobility factor. It is now clear that this covers Jolly and Bolitho's second step of the model, which is "exploration of the need".

This software has provided a considerable amount of English language text about each of the four teams, including images, text, audio and video, as well as hyperlinks to take the students to those teams' websites and their supporters. It is hoped that all of the four English language skills will be practiced. Moreover, the author has provided a chat facility so that learners can produce comprehensible output with each other. If learners' needs and current pedagogical theories are interrelated, then this is an interesting area to investigate in the next section.

\section{English Language Teaching and Design Theories Applied in This Software}

\subsection{Pedagogical Aspects}

The fourth step in Jolly and Bolitho's model is "pedagogical realization”. The importance of considering current pedagogical theories in the specific context underpinning educational software production has been repeatedly asserted by many computer-assisted language learning (CALL) software researchers [4] [8] [9]. Pedagogical theories were in harmony with design theories when the author constructed this software. Reference [10], as an expert in educational interactive media and CALL, accentuates that technology must be seen only as a participant in creating interactive educational media, rather than as a pioneering element. It is with regret that many educational institutions concern themselves with the appliances of multimedia and do not focus on learners' 
needs by producing learner-based design interactive models. This software presents a student-centered design model that can encourage users to have more comprehension utterances. It was achieved by means of providing key linguistic brief chunks. This, coupled with the chat facility, can lead to a facilitative interaction atmosphere among learners [1]. Reference [10], defined seven principles for developing CALL materials: 1) supplying major linguistic quantity, 2) offering modification of the linguistic input, 3) presenting chances for comprehensible output, 4) providing opportunities for noticing errors, 5) providing chances to correct ill-stated output, 6) anchoring friendly interaction between the user and the computer, and 7) playing roles in L2 tasks. The chat facility integrates Chapelle's previously mentioned criteria. A plethora of previous studies conducted in this field have revealed that professionally implemented, interactive educational technology programs (e.g., chat) contributes significantly to fruitful learning experiences [8] [9].

While piloting the first stage of this software, the author noticed that his learners increased their motivation, enhanced their task achievement, and produced greater interaction. Students asked the author to allow them to communicate with other teams' supporters outside the class, but as this was not feasible in this software, the author was unable to fulfill this request. This demonstrates the clear result that students' shyness and inhibitions were minimized. As for the language content, this software focuses on meaning-based learning tasks [8] by providing key dates of the achievements of each of the teams. This was accomplished by supplying a few concise sentences and tables about each of the four teams with visual aids. To tackle the first students' needs of poor linguistic competence, the language was graded from simple to difficult with brief phrases and easy language [8] [9]. Also, the software was targeted to address learners' shyness by designing a user-friendly interface and incorporating easy-to-use navigation, so as to encourage and motivate them to use this software. Reference [1] claimed that computer-assisted class discussion (CACD) is a great equalizer among learners, especially because it targets passive or marginalized students.

In order to deal with students' negative attitudes toward L2, the home page was designed to be engaging and attractive to the students [6]. In an attempt to foster successful language learning, the software utilizes a lot of instructional media, e.g., visuals, sound and videos, so as to be compatible with the learners' preferences and their different learning styles [8]. Reference [3], argues that the more language quantity students are exposed to, the more chances they have to encounter a fruitful language learning environment. Throughout the design process, the idea that this software was created exclusively and privately for Saudi students was heightened. This was achieved by employing a Saudi flag, an avatar of a Saudi boy, and the icon of the institution where they study. Having done this, the third stage of Jolly and Bolitho's model for the production of educational materials was addressed: the "contextualization". According to [6] technology-enhanced designers are strongly encouraged to develop a sense of the cultural awareness of their learners. Failing to do so may cause "learners [to] experience negative feelings in their learning because they think that their entity is put at risk; it distorts their situational and linguistic reality”. Concerning the last aspect, of language learning being kept at class, this can be overcome by the issue of mobility. Reference [4], considers this mobility to be CALL's greatest advantage. This software addressed this and the three preceding aspects of language learning. As this sections shed lights on the design theories underpinning the production of this software, the following section will present a concise outline of the nature and features of this software.

\subsection{Technical Implications}

The application is demonstrated using a Mediator 7 pro, a multimedia authoring icon-based software program. MatchWare Corp. produced this award-winning interactive page-oriented multimedia program that offers a wide range of capabilities such as building pages, adding contents and creating activities. Mediator 7 pro is compatible with HTML, HTML codes and Flashes. Educational aids such as hypertexts, hotspots, and animations can be easily anchored at this educational tool. This multimedia package also allows for chat facility by means of synchronous computer networks and/or connecting to the Internet. The author has implemented this chat facility where the screen is split into two halves: the top half shows students interlocutors' replies; the bottom half shows the students his massage as he is typing. Additionally, it has the facility to save the complete record of any written transactions. This software was designed for first-term students at Madinah College of Technology (MCT), Madinah, Saudi Arabia, studying in the computer department. These students are secondary school graduates who have studied English for six years or more. Their English level is lower-intermediate; however they are good computer users. This icon-based software, as posed earlier, meet the learners' needs as it focuses on in- 
troducing these students to technical English language, namely vocabulary, which they will need in the field of their specialization. Therefore, among the aims of this software is to enable students to comprehend basic technical English in their field as well as preparing them for enrolment in advanced courses of similar nature. As discussed above, while producing this software, Jolly and Bolitho's seven stage model were followed for producing educational material. The next section will resume to illustrate how Jolly and Bolitho's model was applied throughout the production of this software.

In order to meet the fifth step of Jolly and Bolitho's model, which is about the "production of materials". The user-interface is a crucial element that must be taken into consideration when producing interactive educational materials. It can help the user achieve the utmost level of functional competence of the software if applied successfully and efficiently. Reference [11], as a veteran in interactive media, defines the user-interface as the dynamic interaction between the user and the elements that are anchored on the screen. If we recall the objectives of this software, which was receiving and producing comprehensible input, we will find the following quote of [9] worth stating:

The function of the interface system is to assign user-input to internal representations of the application and internal representations of the application to the output that is comprehensible to the user. The type of input and output modes employed by the interface system determines the type of the interface.

Reference [9] (ibid) posed that the user-interface can be classified into one of three categories:

1) Computer-interface: where the functionality relies more on how the computer processes information.

2) User-centered: where the functionality concentrates on how the user processes information.

3) Designer-centered: where the focus is on how the designer prefers to lay out the information.

Although it is clear that the second category is more efficient and beneficial, the current software was done with an equal amount of both the second and the third categories. This is attributed to the fact that the software was designed and produced by an individual teacher, who could not afford to cover the huge expense of constructing it solely based on the second category.

Internal representations to which [9] referred to above were deployed. For example, light brown and yellow colors were used for the background, which, according to [12], can reveal liveliness and friendliness, and help the eye to absorb the elements clearly. However, reference [13] contradicts this argument and states that yellow should be used only for short text due to its bright nature. Following this, the author only used yellow text with a beige background and in short bullet points. The text was kept in the same font, because, according to [6]:

Text has a significant invisible effect on the reader in that every font has three basic attributes: first, size, measured in points; second, weight, which is a "relative measurement of the thickness of the strokes that make it up"; and third, style, which is Roman, Bold or Italic. Changing font means changing these three attributes.

Moreover, the layout was also an important parameter. According to [13] "the position of the separate elements in relation to the screen and in relation to each other" must be consistent throughout the whole website. Thus, the author incorporated the same colors and shaped buttons for the comparable tasks. For example, on every team's pages, the user finds the same colored background and can find the navigation buttons anchored at the lower part of the page with the same dark red colors. Finally, pictures, as a vital part of the internal representations, were meant as a visual explanation for the text or labels. Researchers stress the fact that images should not be used for decorative purposes only [11]; Thissen, 2004 [4]. The next section investigates one of the most pivotal stages of computer-aided educational materials: evaluation.

\section{Evaluation of the Strong and the Weak Aspects of This Software}

As this software adopted Jolly and Bolitho's model for the production of educational materials, the sixth step "students' use of material” was conducted. The student used the software and the author observed them. This authors' observation helped gain a more genuine sense about the "technical considerations, e.g. installation and networking; multimedia design criteria, e.g. aesthetics and help; and pedagogical factors, e.g. integration and fulfillment of learning objectives” [6]. This step paved the way for applying the last step in [5], model which is "evaluation". First, the author needs to highlight the fact that he, as an individual, faced some problems in constructing this software. The economical restrictions, or what has recently been called the "bleeding edge" of the resources, i.e., that some resources are very expensive, and the author was not capable of paying for those resources. If this software was professionally constructed and generously subsidized, it would have fewer inadequacies in both theoretical and technical aspects. 
Some of the weak points of this software will be discussed. For example, some very authentic and useful English media for the Barcelona team was available, but due to its relatively high price, this software used some free Internet media instead, whose quality was not very remarkable. Even though it was free, it took the author hours to find due to the cultural sensitivity issues associated with Saudi students. Reference [1] elaborated on this issue further in his article, and this subject is beyond the scope of this paper. The fair skill level in programming yielded some limitations to this software. Had there been some professional help in Flash media, there would have been great software. In particular, editing the video clips was very debilitating and annoying, due to the aforementioned factor of cultural sensitivity. This was not the case with the pictures, because the author was able to edit, crop, and even create his own pictures. Moreover, the sound files are not yet completed as initially planned. Instead, the students can click a hyperlink where they are transferred to a YouTube page to listen to the sound files. Most of these sound files were interviews and official torhymne. A trohymne is a playable unique sound for a club or a university. Concerning authentic tasks for the software, the previous limitations have minimized the quality and quantity of the tasks. For instance, the author planned to add some games or tasks inside the authentic source, such as recording video of a technical analysis of a match. However, this has not been feasible due to limitations stated earlier.

In spite of these weaknesses, this software has many strong points. First, the students stressed the fact that they were very happy and surprised to see their favorite hobby being practiced in English rather than dull ready-course-materials. In fact, this attitude is very profitable to language learning, and is called "learner-driven curriculum" [3]. They also expressed their smooth ease with the navigation. Furthermore, the readability of the text, the continuity of information, and the consistency of the screen layout was also praised by the students. They found the experience appealing, constructive, and profitable, which pushed them to request to try the software once again. Most significantly, they liked the idea of the chat very much, because it was full of enthusiasm and interesting. This evaluation of the pros and cons of the software led me to think about how the disadvantages could be addressed in the post-production phase, which the next section discusses.

\section{Further Development}

The prospect of the post-production development of any technology-enhanced material is a great advantage in comparison with paper-based material. In the previous sections, a number of improvements were suggested, some of which are indispensable. To begin with, this software should encompass more teams, because while piloting, the author discovered students who wanted to support more than one international team that were in different countries. So, the author wishes to add Bayern-Munich (Germany), Paris Saint-German (France), F. C. Porto (Portugal), and Galatasaray (Turkey). These teams were nominated by the students, not by the author. In addition, it would be more interesting if the author could provide subtitles with the sound files so that the students could practice both skills of listening and reading. If a visual explanation of the sounds on the screen could be provided, online dictionaries for those words could also be provided. Additionally, some difficult sound files, like the interviews, could be replaced by the author's recorded voice, because the students were more apt to comprehend slower conversations than faster ones. With the cooperation of other supporters from international countries, this software can connect Saudi students to chat with the same team's supporters or advocates from international countries. This would create collaborative learning and scaffolding, especially if they are both non-native speakers and share the same interests [1]. By doing this we can maximize the chances of providing all seven of the criteria posed earlier by [10].

The influence of video games nowadays cannot be ignored; the students are seeing a great demand for adding short clips. By doing this, we can find exactly what we need to show or convey instead of a long and thorough Internet search for a specific bit of information. For example, at one of the texts, there is a scenario where the goalkeeper scores a goal in the other team. The internet search yielded no result. With this video game, we will be able to create the scenario we want. Also, we can organize championships and leagues and divide students into two teams. Each team has players and supporters. This will be an interaction inducing atmosphere.

\section{Conclusion}

A great deal of potential of this software is missing due to the author's limited skills in programming; with this knowledge from experts in programming, the prototype can be vastly improved. This software failed to record students discourse both verbal and written. With this facility installed in the software, we can monitor the stu- 
dents' improvements by making a discourse analysis for the students' output. In this sense, the software can enter an add-in process, where an unprecedented, professional, and promising piece of technology-enhanced interactive software is created.

\section{References}

[1] Alahmadi, B. (2007) The Viability of Computer-Assisted Class Discussion CACD as a Facilitator of Communicative Interaction. Jaltcall, 3, 3-32.

[2] Nunan, D. (1994) The Learner Centred Curriculum. Cambridge University Press, Cambridge.

[3] Beatty, K. (2003) Teaching and Researching Computer-Assisted Language Learning. Longman, London.

[4] Hubbard, P.L. (1996) Elements of CALL Methodology: Development, Evaluation, and Implementation. In: Pennington, M.C. and Stevens, V., Eds., The Power of CALL, Athelstan, Bolsover, Houston, 15-32.

[5] Jolly, D. and Bolitho, R. (1998) A Framework for Materials Writing. In: Tomlinson, B., Ed., Materials Development in Language Teaching, Cambridge University Press, Cambridge, 90-115.

[6] Alahmadi, B. (2010) Interface Design Theories of Foreign Language Multimedia Software. ICIMIT IEEE CFP10531PRT, 540-544.

[7] Abu Ghararah, A. (1998) Teaching English as a Foreign Language: Procedures, Techniques and Activities. Tawbah Library, Riyadh.

[8] Peterson, M. (2000) Directions for Development in Hypermedia Design. Computer Assisted Language Learning, 13, 253-269. http://dx.doi.org/10.1076/0958-8221(200007)13:3;1-3;FT253

[9] Plass, J.L. (1998) Design and Evaluation of the User Interface of Foreign Language Multimedia Software: A Cognitive Approach. Language Learning \& Technology, 2, 35-45.

[10] Chapelle, C. (1998) Multimedia CALL: Lessons to Be Learned From Research on Instructed SLA. Language Learning and Technology, 2, 22-34.

[11] Elsom-Cook, M. (2001) Principles of Interactive Multimedia. McGraw-Hill, London.

[12] Thissen, F. (2004) Screen Design Manual. Communicating Effectively through Multimedia. Series X, Springer, Berlin.

[13] Barfield, L. (2004) Design for New Media Interaction Design for Multimedia and the Web. Pearson Education Limited, Harlow. 